\title{
Pengaruh Model Pembelajaran Permainan Sirkuit Terhadap Peningkatan Kebugaran Jasmani Dan Motivasi Belajar Siswa Dalam Pembelajaran PJOK
}

\author{
${ }^{1}$ Tara Rhiskita Citra Beauty, ${ }^{2}$ Nurhasan, ${ }^{3}$ Abdul Rachman Syam Tuasikal \\ Program Studi Pendidikan Olahraga, Program Pascasarjana Universitas Negeri Surabaya \\ Email: taracb345@gmail.com
}

\begin{abstract}
Abstrak. Penelitian ini bertujuan untuk mengetahui pengaruh model pembelajaran permainan sirkuit terhadap peningkatan kebugaran jasmani dan motivasi belajar siswa dalam pembelajaran PJOK. Metode yang digunakan dalam penelitian ini adalah penelitian eksperimen dengan pendekatan kuantitatif dengan rancangan matching only design. Pada penelitian ini terdapat kelompok kontrol, kelompok eksperimen dengan adanya perlakuan, adanya pretest-posttest untuk memastikan efektifitas perlakuan yang diberikan. Dua kelas dari sembilan kelas pada lingkup penelitian yang akan dijadikan sampel, satu kelas sebagai kelompok kontrol dan satu kelas sebagai kelompok eksperimen. Pemilihan sampel menggunakan teknik cluster random sampling dengan melakukan undian secara acak. Hasil uji paired sample t-test dalam kelompok eksperimen menunjukkan pengaruh yang signifikanpada variabel kebugaran jasmani memiliki signifikansi 0,000 dengan peningkatan sebesar $11 \%$ dan motivasi belajar memiliki signifikansi 0,000 dengan peningkatan 10\%. Dengan demikian, disimpulkan dari penelitian ini bahwa model pembelajaran permainan sirkuit pada pembelajaran PJOK dapat meningkatkan kebugaran jasmani dan motivasi belajar.
\end{abstract}

\section{Kata Kunci: Model pembelajaran permainan sirkuit, Kebugaran jasmani, Motivasi belajar.}

\section{PENDAHULUAN}

Pendidikan menjadi kebutuhan yang mendasar bagi setiap manusia demi menjamin keberlangsungan hidup dimasa sekarang maupun masa yang akan datang, ini berarti bahwa pendidikan harus bisa memenuhi kebutuhan dasar setiap peserta didik yang mengikuti proses pembelajaran. Peserta didik harus nyaman dan aktif saat mengikuti proses pembelajaran yang di dirancang oleh guru. Pembelajaran yang dirancang harus bisa memberikan pengalaman gerak untuk menunjang pertumbuhan dan perkembangan peserta didik. Kemampuan pola gerak tersebut diperoleh dan dikembangkan secara bersama ketika peserta didik menerima materi pelajaran pas saat proses belajar mengajar. Hal ini bertujuan agar peserta didik mampu berdaya saing dan mandiri di kehidupan sekarang maupun dikehidupan yang akan datang.

Melalui pendidikan juga akan dibentuk karakter seseorang menjadi lebih baik, sehingga dengan demikian tujuan pendidikan dapat tercapai. Seperti yang disampaikan Hamalik (2010, p.58) "Mengajar adalah membimbing kegiatan belajar anak, mengajar adalah membantu murid mencapai tujuan belajar”. Karena Pendidikan Jasmani Olahraga dan Kesehartan (PJOK) juga merupakan bagian dari sistem (kurikulum) pendidikan secara keseluruhan, maka tidak terberlebihan apabila tujuan pendidikan ini juga dapat diwujudkan melalui mata pelajaran PJOK di sekolah-sekolah. Senada dengan apa yang disampaikan Kristiyandaru (2012, p.33) juga mengatakan bahwa PJOK adalah bagian integral dari pendidikan keseluruhan yang mengutamakan aktivitas jasmani dan pembinaan hidup sehat untuk pertumbuhan dan perkembangan jasmani, mental, sosial, dan emosional yang serasi, selaras, dan seimbang. Dari beberapa pendapat di atas, dapat penulis simpulkan bahwa PJOK merupakan bagian dari proses pendidikan, dan hasilnya adalah karakter dan pola gerak.

Pendidikan formal di Indonesia PJOK sudah dimulai sejak dasar, yaitu sejak Sekolah Dasar (SD), Sekolah Menengah Pertama (SMP), dan Sekolah Menengah Atas (SMA), bahkan sampai perguruan tinggi, ini membuktikan bahwa PJOK merupakan mata pelajaran yang penting, karena melalui PJOK peserta didik dapat menyalurkan kebutuhan dan keinginan untuk bergerak, disamping itu 
juga dapat juga memberi kesempatan kepada para peserta didik untuk terlibat secara langsung dalam berbagai pengalaman belajar melalui aktivitas jasmani. Kebugaran jasmani merupakan aspek yang sangat penting dimiliki setiap orang. Gu dan chang (2016) menyatakan bahwa dengan meningkatkan kebugaran jasmani anak-anak dapat memfasilitsai hasil positif termasuk kualitas kesehatan terkait peningkatan kehidupan. Senada dengan pendapat ini, Kemendikbud (2014, p.124) menyatakan kebugaran jasmani adalah kesanggupan dan kemampuan tubuh melakukan penyesuaian terhadap pembebanan fisik yang diberikan (dari kerja yang dilakukan sehari-hari) tanpa menimbulkan kelelahan yang berati, dari pengertian tersebut dapat diartikan jika seseorang yang memiliki kebugaran jasmani yang baik maka dia akan dapat melakukan kegiatan yang dilakukan sehari-hari tanpa merasakan kelelahan yang akan mengganggunya untuk melakukan suatu pekerjaan lainnya. Sedangkan menurut (Sahrial, 2017, p.1) kebugaran jasmani mampu mengadaptasi segala beban fisik maupun psikis yang diterima, dimana menjadi salah satu media yang dapat mendorong pertumbuhan fisik, perkembangan psikis, keterampilan motorik, pengetahuan dan penalaran.

Dalam dunia pendidikan, pembelajaran PJOK harus mampu memberikan aktifitas fisik yang cukup suntuk peserta didik agar memiliki kebugaran jasmani yang baik. Menurut shape of the nation (2016, p.3) mengatakan bahwa "physical education program are a meaningful contributor to the development of healthy, active children and provide the save, supervised, structured enivornment children need to learn and practice physically active behaviors" sedangan menurut sriundy (2014, p.126) "tujuan mata pelajaran penjasorkes untuk meningkatkan kebugaran jasmani peserta didik diamanahkan di semua jenis dan jenjang pendidikan." Diharapkan dengan pelaksanaan dari mata pelajaran PJOK ini peserta didik akan memiliki kebugaran jasmani yang bagus dan dapat menunjang pembelajaran, sehingga dapat terwujud tujuan pendidikan nasional. (Lutan, 2002, p.3) juga mengemukakan bahwa pemahaman konsep kebugaran jasmani dan aktivitas jasmani bertujuan untuk mencapai keadaan sehat. Jadi diharapkan melalui pendidikan jasmani olahraga dan kesehatan siswa dapat memahami apa itu kebugaran jasmani, aktivitas yang harus dilakukan dan hasil akhir yang dicapai melalui aktivitas jasmani. Dengan memberi aktivitas jasmani yang bertujuan untuk kebugaran siswa, guru dituntut agar pembelajaran yang diberikan menyenangkan sehingga dapat memotivasi siswa untuk mengikuti pembelajaran PJOK.

Dalam kegiatan belajar mengjar pemberian penguatan dirasa penting agar siswa memiliki konsep diri positif sehingga motivasi siswa menjadi tinggi untuk mengikuti pembelajaran (Setyorini, 2016, p.8). Motivasi dapat dikatakan sebagai salah satu hal penting saat pembelajaran berlangsung, karena saat siswa mengikuti proses belajar mengajar diharapkan siswa mengikuti dengan antusias dan semangat terhadap materi pembelajaran. Menurut Maksum (2011, p.71) dilihat dari sumbernya, motivasi seseorang bias intrinsik dan ekstrinsik, yang dimaksud motivasi intrinsik yaitu motivasi yang timbul dari dalam diri sendiri tanpa ada pengaruh dari luar, seperti saat siswa memotivasi dirinya sendiri untuk bias melakukan suatu tugas gerak. Sedangkan motivasi ekstrinsik yaitu motivasi yang berasal dari luar, seperti saat siswa berhasil melakukan tugas gerak dengan baik, maka akan ada kepuasan dalam diri sendiri. Maka dari itu dalam suatu pembelajaran dibutuhkan suatu metode yang baik agar dapat meningkatkan motivasi siswa untuk mengikuti pembelajaran. Selain itu dalam lampiran permendikbud nomor 22 tahun 2016 tentang standart proses pendidikan dasar dan menengah bab 1 menyebutkan juga bahwa "proses pembelajaran pada satuan pendidikan diselenggarakan secara interaktif, inspiratif, menyenangkan, menantang, memotivasi peserta didik untuk berpartisipasi aktif, serta memberikan ruang yang cukup bagi prakarsa, kreativitas dan kemandirian sesuai dengan bakat, minat dan perkembangan fisik serta psikologis peserta didik."

Dari hasil wawancara dengan Guru di SMP 2 Madiun diperoleh keterangan bahwa tingkat kebugaran jasmani peserta didik masih 
kurang, hal ini disebabkan karena daya dukung sekolah masih belum memadai, sehingga proses belajar mengajar PJOK terkesan kurang menarik, metode yang digunakan cenderung metode konvensional yang berpusat pada guru, akibatnya minat belajar dan kreativitas peserta didik sangat kurang karena mereka hanya mengikuti komando dari guru. Untuk menarik minat belajar peserta didik, dibutuhkan kreatifitas seorang guru, sehingga dalam proses belajar mengajar guru dituntut untuk mencari dan menemukan metode atau strategi pembelajaran seperti apa yang yang cocok untuk diterapkan dalam mengatasi masalahmasalah yang dihadapi peseta didik kelas VII di SMP Negeri 2 Madiun.

Banyak upaya yang dapat digunakan guru untuk menarik perhatian peserta didik dalam pembelajaran, satu diantaranya adalah dengan permainan, mengingat pada peserta didik yang baru masuk SMP, cenderung akan membawa kebiasaannya pada saat sekolah dasar yang masih menyukai bermain, aktif dan penuh semangat, kerena tidak hanya anak usia dini saja bahkan remaja maupun dewasa juga membutuhkan bermain untuk mencukupi kebutuhan gerak sekaligus bersifat rekreasi (Hartati, 2012, p.1). Permainan aktvitas sirkuit bisa menjadi salah satu upaya dalam pemberian materi pada pembelajaran PJOK ini dillihat dari hasil penelitian Latif (2018) dapat di simpulkan bahwa permainan aktivitas sirkuit dapat meningkatkan hasil belajar kebugaran jasmani pesrta didik Kelas VIII SMP Negeri 5 Yogyakarta.

Penelitian ini bertujuan untuk mengetahui pengaruh model pembelajaran permainan sirkuit terhadap peningkatan kebugaran jasmani dan motivasi belajar siswa dalam pembelajaran PJOK.

\section{METODE}

Metode yang digunakan dalam penelitian ini adalah penelitian eksperimen dengan pendekatan kuantitatif dengan rancangan matching only design. Rancangan ini terdapat kelompok kontrol, adanya perlakuan, adanya pretest-posttest untuk memastikan efektifitas perlakuan yang diberikan. Adapun desain/rancangan penelitiannya adalah sebagai berikut.

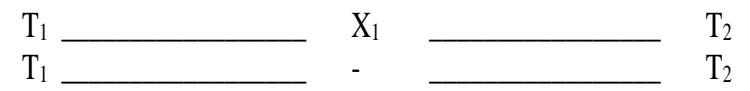

$\mathrm{T}_{1}$ sebagai tes awal (pre-test), $\mathrm{X}_{1}$ merupakan proses pembelajaran dengan sirkuit, dan $\mathrm{T}_{2}$ sebagai tes akhir (post-test).

Populasi dalam penelitian ini adalah semua siswa SMP kelas VII SMP Negeri 2 Madiun. Sampel penelitian sebanyak 2 kelas dari 9 kelas, dan terambil Kelas VII B sebagai kelompok eksperimen, dan kelas VII E sebagai kelompok kontrol. Teknik pengambilan sampel dalam penelitian ini menggunakan cluster random sampling. Dalam teknik cluster random sampling yang dipilih bukan individu, melainkan kelompok atau area yang kemudian disebut cluster (Maksum, 2012, p.57). Cara menentukan kelompok kontrol dan kelompok eksperimen yaitu dengan melakukan undian secara acak yang disaksikan oleh guru dan perwakilan dari seluruh kelas VII, sehingga terambil 2 kelompok sampel, setelah terambil 2 kelompok sampel maka akan diundi secara acak lagi untuk menentukan kelompok mana yang menjadi kelompok kontrol dan kelompok eksperimen. Penelitian ini berlangsung 6 minggu, dimana 1 minggu pertama untuk tahap persiapan dan pretest 4 minggu untuk pemberian perlakuan (treatment) dengan frekwensi 4 kali pertemuan dan minggu terakhir untuk posttest. Penelitian ini dimulai 25 Februari - 31 Maret 2020.

Instrumen yang digunakan untuk mengukur kebugaran jasmani peserta didik adalah Tes Kesegaran Jasmani Indonesia (TKJI) level Sekolah Menengah Pertama, yaitu; a) lari 50 meter, b) tes gantung angkat tubuh untuk putra, tes gantung siku tekuk untuk puteri, c) baring duduk 60 detik, d) loncat tegak, dan e) lari 1000 meter putra dan 800 meter untuk putri. Instrumen untuk mengukur motivasi, yaitu angket (kuesioner) motivasi siswa sebanyak 28 pertanyaan dengan skala likert. Data dianalisis secara statistik dengan uji Anova yang didahului uji prasyarat (uji homogenitas dan normalitas) masing-masing pada taraf signifikansi $\alpha=0.05$.

\section{HASIL DAN PEMBAHASAN}


Deskripsi hasil pretest dan posttest untuk tiap kelas seperti disajikan pada Tabel 1 dan Tabel 2.

Tabel 1. Deskripsi hasil data awal (pretest)

\begin{tabular}{|c|c|c|c|c|c|}
\hline Kelas & Statistik & Minimum & Maximum & Mean & Std. Dev \\
\hline \multirow{2}{*}{ Kontrol } & Sirkuit & 10 & 16 & 12,5000 & 1,64429 \\
\cline { 2 - 6 } & Motivasi & 96 & 115 & 104,0357 & 5,13869 \\
\hline \multirow{2}{*}{ Perlakuan } & Sirkuit & 11 & 18 & 12,8571 & 1,53271 \\
\cline { 2 - 6 } & Motivasi & 98 & 118 & 105,5357 & 5,04412 \\
\hline
\end{tabular}

Tabel 2. Deskripsi hasil post test

\begin{tabular}{|c|c|c|c|c|c|}
\hline Kelas & Statistik & Minimum & Maximum & Mean & Std. Dev \\
\hline \multirow{2}{*}{ Kontrol } & Sirkuit & 10 & 16 & 12,6071 & 1,64067 \\
\cline { 2 - 6 } & Motivasi & 96 & 115 & 104,0714 & 5,13869 \\
\hline \multirow{2}{*}{ Perlakuan } & Sirkuit & 11 & 18 & 14,2857 & 1,65232 \\
\cline { 2 - 6 } & Motivasi & 98 & 125 & 115,6071 & 6,56782 \\
\hline
\end{tabular}

Tabel 1 dan Tabel 2 menunjukkan gambaran data yang akan dianalisis selanjutnya yaitu data rata-rata, standart deviasi, nilai maksimal dan nilai minimal. Penghitungan data secara deskriptif, didapatkan perubahan nilai hasil pemberian perlakuan. Selanjutnya untuk mengetahui hasil dari perubahan data setelah diberikan perlakuan akan dijabarkan pada Tabel 3 .

Tabel 3. Perubahan hasil penelitian skor hasil pre test dan post test

\begin{tabular}{|c|c|c|c|c|}
\hline Kelas & Statistik & Pree Test & Post Test & Selisih \\
\hline \multirow{2}{*}{ Kontrol } & Sirkuit & 12,5000 & 12,6071 & 0,1071 \\
\cline { 2 - 5 } & Motivasi & 104,0357 & 104,0714 & 0,0357 \\
\hline \multirow{2}{*}{ Perlakuan } & Sirkuit & 12,8571 & 14,2857 & 1,4286 \\
\cline { 2 - 5 } & Motivasi & 105,5357 & 115,6071 & 10,0714 \\
\hline
\end{tabular}

Uji normalitas dibutuhkan untuk memastikan bahwa data yang diperoleh berdistribusi normal. Uji normalitas dapat menggunakan metode shapiro-wilk. Jika taraf signifikasi dalam uji statistik lebih besar dari 0.05 maka dinyatakan normal, sebaiknya jika taraf signifikasi dalam uji statistik lebih kecil dari 0.05 maka dinyatakan tidak normal. Tabel 4 mendeskripsikan hasil uji normalitas.

Tabel 4. Hasil Uji normalitas pretest dan posttest

\begin{tabular}{|c|c|c|c|c|c|}
\hline Variabel & Test & $\begin{array}{c}\text { Eksperimen } \\
\text { Sig }\end{array}$ & $\begin{array}{c}\text { Kontrol } \\
\text { Sig }\end{array}$ & Ket & Status \\
Kebugaran & Tes Awal & 0,215 & 0,195 & $\mathrm{P}>0,05$ & Normal \\
\cline { 2 - 6 } Jasmani & Tes Akhir & 0,164 & 0,222 & $\mathrm{P}>0,05$ & Normal \\
\hline $\begin{array}{c}\text { Motivasi } \\
\text { belajar }\end{array}$ & Tes Awal & 0,225 & 0,128 & $\mathrm{P}>0,05$ & Normal \\
\cline { 2 - 6 } & Tes Akhir & 0,126 & 0,155 & $\mathrm{P}>0,05$ & Normal \\
\hline
\end{tabular}

Hasil pada Table 4 menunjukkan bahwa besarnya nilai Sig. (2 tailed) dari kedua kelompok menunjukkan angka yang lebih besar dari 0.05. Dengan begitu sesuai dengan kriteria pengujian bahwa data dari kedua kelompok tersebut berdistribusi normal. Setelah melakukan uji normalitas langkah berikutnya adalah melakukan uji homogenitas variansi skor data awal pre test dan skor data akhir post test. Uji homogenitas bertujuan untuk memastikan bahwa varian dari setiap kelompok sama atau sejenis, sehingga perbandingan dapat dilakukan secara adil (Maksum: 2012, p.162). Penelitian ini menggunakan lavene's test. Apabila nilai statistic lavene's test lebih besar dari 0.05 maka data dapat dikatakan memiliki varian yang homogen. Hasil uji homogenitas disajikan pada Tabel 5 dan Tabel 6 .

Tabel 5. Hasil uji homogenitas skor pre test

\begin{tabular}{|l|c|c|c|}
\hline Variabel & Levene Statistic & Sig. & Keterangan \\
\hline Pree Test Kebugaran Jasmani & 0,551 & 0,461 & Homogen \\
\hline Pree Test Motivasi Belajar & 0,444 & 0,508 & Homogen \\
\hline
\end{tabular}

Tabel 6. Hasil uji homogenitas skor post test

\begin{tabular}{|l|c|c|c|}
\hline Variabel & Levene Statistic & Sig. & Keterangan \\
\hline Post Test Kebugaran Jasmani & 0,83 & 0,774 & Homogen \\
\hline Post Test Motivasi Belajar & 0,776 & 0,382 & Homogen \\
\hline
\end{tabular}

Berdasarkan hasil pada Tabel 5 dan Tabel 6, menunjukkan bahwa perolehan data kedua variabel terikat kebugaran jasmani dan motivasi belajar memiliki varians homogen. Hal ini dimaknai oleh karena nilai signifikansi dari masing-masing data menunjukkan taraf signifikansi atau $(p)>0,05$. Sehingga dapat disimpulkan bahwa varians pada tiap kelompok adalah sama atau homogen.dengan begitu penghitungan dapat dilanjutkan untuk uji hipotesis.

Analisis paired sampel t-test digunakan untuk mengetahui apakah terdapat pengaruh yang signifikan dari perlakuan atau treatment yang telah dilakukan. Berdasarkan hasil uji prasyarat yang telah dilakukan pada pembahasan yang telah dilakukan sebelumnya maka diketahui bahwa data dari seluruh variabel memiliki distribusi normal dan memiliki varian yang sama atau homogen. Setelah mengetahui data normal dan homogen maka uji statistik slanjutnya yang digunakan adalah analisis uji statistik parametrik. Dalam penghitungan analisis kali ini akan 
mengabaikan kelompok kontrol. Hal ini dikarenakan kelompok kontrol tidak diberikan perlakuan khusus atau treatment. Selanjutnya dijabarkan hasil analisis pengaruh dari treatment yang diberikan kepada para sampel. Hasil paired $t$ test kelompok perlakuan disajikan pada Tabel 7.

Tabel 7. Hasil paired sample t test kelompok perlakuan

\begin{tabular}{|l|l|c|}
\hline \multicolumn{2}{|c|}{} & Sig. (2-tailed) \\
\hline \multirow{2}{*}{ Perlakuan } & Pre - Post Kebugaran Jasmani & 0,000 \\
\cline { 2 - 3 } & Pre - Post Motivasi Belajar & 0,000 \\
\hline
\end{tabular}

Data signifikansi dari hasil analisis yang didapatkan adalah 0,000 atau Sig. < 0,05. Maka terdapat pengaruh yang signifikan dari kelompok perlakuan terhadap kebugaran jasmani. Signifikansi data yang didapatkan oleh motivasi belajar adalah 0,000 atau Sig. < 0,05 . Maka terdapat pengaruh signifikan dari kelompok perlakuan terhadap motivasi belajar. Untuk lebih memahami ada pengaruh atau tidaknya kelompok perlakuan terhadap kebugaran jasmani dan motivasi belajar akan dilihat pada Tabel 8.

Tabel 8. Pengaruh pemberian perlakuan

\begin{tabular}{|c|c|c|}
\hline Metode & Variabel & Pengaruh \\
\hline \multirow{2}{*}{ Perlakuan } & Kebugaran Jasmani & Ada \\
\cline { 2 - 3 } & Motivasi Belajar & Ada \\
\hline
\end{tabular}

Hasil paired t test kelompok perlakuan disajikan pada Tabel 9.

Tabel 9. Hasil paired sample t test kelompok kontrol

\begin{tabular}{|c|l|c|}
\hline \multicolumn{2}{|c|}{} & Sig. (2-tailed) \\
\hline \multirow{2}{*}{ Kontrol } & Pre - Post Kebugaran Jasmani & 0,083 \\
\cline { 2 - 3 } & Pre - Post Motivasi Belajar & 0,802 \\
\hline
\end{tabular}

Data signifikansi dari hasil analisis yang didapatkan oleh kebugaran jasmani adalah 0,083 atau Sig. > 0,05. Maka tidak terdapat pengaruh yang signifikan dari kelompok control terhadap kebugaran jasmani. Signifikansi data yang didapatkan oleh motivasi belajar adalah 0,802 atau Sig. > 0,05. Maka tidak terdapat pengaruh signifikan dari kelompok control terhadap motivasi belajar. Tabel 10. Pengaruh pemberian kontrol

\begin{tabular}{|c|c|c|}
\hline Metode & Variabel & Pengaruh \\
\hline \multirow{2}{*}{ Kontrol } & Kebugaran Jasmani & Tidak Ada \\
\cline { 2 - 3 } & Motivasi Belajar & Tidak Ada \\
\hline
\end{tabular}

Pengujian beda rerata antar kelompok secara bersamaan dilakukan dengan menggunakan Analisis Varians (Anova). Menurut Maksum (2012) One Way Anova adalah teknik statistik parametrik yang digunakan untuk menguji perbedaan antara dua atau lebih kelompok data. Hasil perhitungan uji beda antar kebugaran jasmani dan motivasi disajikan pada Tabel 11.

Tabel 11. Hasil perhitungan uji beda antar kebugaran jasmani dan motivasi

\begin{tabular}{|l|c|c|}
\hline \multicolumn{1}{|c|}{ Test } & F_hitung & Sig. \\
\hline Kebugaran Pre & 0.707 & 0,404 \\
\hline Kebugaran Post & 14,551 & 0,000 \\
\hline Motivasi pre & 1,215 & 0,275 \\
\hline Motivasi Post & 53,668 & 0,000 \\
\hline
\end{tabular}

Berdasarkan Tabel 11 hasil perhitungan uji beda antar kelompok menggunakan One Way Anova dapat disimpulkan bahwa terdapat perbedaan yang signifikan antara hasil penerapan permainan pada kelompok eksperimen, dan kelompok kontrol terhadap kebugaran jasmani dan motivasi belajar, karena hasil perhitungan posttest kebugaran jasmani menunjukkan nilai $\mathrm{Sig}<0,05$ dan posttest motivasi belajar menunjukkan nilai Sig < dari $\alpha=0,05$.

Berdasarkan hasil perlakukan pada kelompok eksperimen peningkatan signifikansi yang di dapat adalah 0,000 atau Sig. < 0,05 Maka terdapat pengaruh signifikansi terhadap peningkatan kebugaran jasmani. Melalui permainan sirkuit kebugaran jasmani siswa di SMP Negeri 2 Madiun mengalami peningkatan hal ini di dukung oleh penelitian sebelumnya Iwan (2015) dimana terdapat peningkatan kebugaran jasmani pad siswa dengan menggunakan tes kesegaran jasmani indonesia (TKJI). Dalam proses pembelajaran melalui permainan sirkuit di SMP Negeri 2 Madiun model permainan disesuaikan dengan karakteristik dan kemampuan siswa menengah pertama dimana dalam model sirkuit ini memberikan unsur permainan yang membuat anak- anak tidak mudah merasa boan dan terpacu untuk melakukan semua aktivitas gerak yang sudah 
di siapkan di pos masing- masing. Model permainan sirkuit ini mencangkup komponen kebugaran jasmani yaitu kelincahan, kekuatan, power, keseimbangan dan koordinasi. Hasil dalam penelitian ini siswa mengalami peningkatan sebesar $11 \%$ sesudah di berikan perlakuan model pembelajaran permainan sirkuit.

Hasil perlakukan pada kelompok eksperimen peningkatan signifikansi yang di dapat adalah 0,000 atau Sig. < 0,05 Maka terdapat pengaruh signifikansi terhadap peningkatan motivasi belajar peserta didik dalam pembelajaran PJOK. Dengan menggunakan model pembelajaran permainan sirkuit dapat meningkatkan motivasi belajar siswa untuk mengikuti pembelajaran PJOK di SMP Negeri 2 Madiun, hal ini dapat dilihat dari peningkatan motivasi belajar siswa yang meningkat sebesar $10 \%$ peningkatan ini di dukung dengan penelitian sebelumnya Asrul (2018), di mana dalam penelitian ini untuk meningkatkan motivasi belajar siswa peneliti memberikan kegiatan pembelajaran PJOK menggunakan model permainan. Dengan karakteristik anak sekolah menengah pertama akan lebih bersemangat jika menggunakan metode pembelajaran permainan dikarenakan masa transisi dari anak sekolah dasar yang masing sangat aktif bergerak.

Secara keseluruhan dari hasil perhitungan setelah diberi perlakuan berupa permainan selama empat kali pertemuan selama empat minggu, pada kelompok eksperimen terjadi peningkatan yang signifikan. Sehingga dalam hal ini dapat disimpulkan bahwa terdapat pengaruh penerapan model pembelajaran terhadap peningkatan kebugaran jasmani dan motivasi belajar peserta didik dalam pembelajaran PJOK. Hasil penelitian tentang peranan model pembelajaran permainan sirkuit memang dapat meningkatkan hasil belajar peserta didik dalam pembelajaran PJOK, akan tetapi hasil tersebut tidak dapat dijadikan sebagai landasan bahwa dengan menerapkan model pembelajaran tersebut dalam proses pembelajaran akan berpengaruh besar untuk meningkatkan kebugaran jasmani dan motivasi peserta didik. Hal tersebut dikarenakan masih terdapat faktor-faktor lain yang dapat mampengaruhinya, seperti yang dikatakan oleh beberapa ahli diantaranya Menurut Nurhasan (2011, p.19) terdapat 2 faktor yang dapat mempengaruhi kebugaran jasmani, faktor Internal yang meliputi genetik, umur dan jenis kelamin sedangkan, untuk faktor Eksternal meliputi aktivitas fisik, kebiasaan olahraga, status gizi, kadar hemoglobin, kebiasaan merokok, status kesehatan, dan kecukupan istirahat.

Menurut Hamalik (2010, p.179) faktorfaktor yang mempengaruhi motivasi ialah umur, kondisi fisik, kekuatan inteligensi, model dan lingkungan. Pada penelitian ini kebugaran jasmani dan motivasi yang meningkat dipengaruhi oleh guru, model pembelajaran, kondisi fisik dan lingkungan sekolah, sehingga hal ini dapat membatu peserta didik termotivasi untuk mengikuti pembelajaran penjasorkes di sekolah. Pada penelitian ini teori-teori tersebut bekerja pada peningkatan hasil belajar peserta didik dalam pembelajaran PJOK.

Deskripsi tersebut menunjukkan bahwa strategi, metode dan model pembelajaran dapat membantu perkembangan seseorang diantaranya seperti perkembangan fisik, motorik, serta perkembangan pola piker dan emosi seseorang. Pada penelitian ini peserta didik mencoba secara langsung kegiatan pembelajaran dengan menggunakan model pembelajaran permainan sikuit, sehingga membuat peserta didik merasakan langsung kegiatan pembelajaran dan dapat merasakan suatu aktivitas belajar yang baru, dan diharapkan membantu meningkatkan hasil belajarnya melalui model pembelajaran tersebut.

\section{KESIMPULAN}

Hasil uji paired sample t-test dalam kelompok eksperimen menunjukkan pengaruh yang signifikanpada variabel kebugaran jasmani memiliki signifikansi 0,000 dengan peningkatan sebesar $11 \%$ dan motivasi belajar memiliki signifikansi 0,000 dengan peningkatan $10 \%$. Dengan demikian, disimpulkan dari penelitian ini bahwa model pembelajaran permainan sirkuit pada pembelajaran PJOK dapat meningkatkan kebugaran jasmani dan motivasi belajar. 


\section{DAFTAR PUSTAKA}

Akbar, Sa'dun. (2015). Instrumen Perangkat Pembelajaran. Bandung: Remaja Rosda Karya.

Anwar, Ahmad Zuhrotil. (2017). Pengaruh Peneran Permainan Terhadap Peningkatan Kemampuan Motorik Dan Motivasi Belajar Siswa Dalam Pembelajaran PJOK Pad Siswa Kelas VII SMP Negeri 4 Lamongan. Tesis Tidak Diterbitkan. Surabaya: Pascasarjana.

Ardyansyah, Ari (2015). Pengaruh Reward Terhadap Motivasi Belajar Siswa Dalam Pembelajaran Penjasorkes Pad Siswa SMA Negeri 2 Kota Mojokerto. Tesis Tidak Diterbitkan. Surabaya: Pascasarjana Unesa

Aris, Risyanto. (2017). Hubungan Motivasi Belajar Siswa Dengan Hasil Belajar Pendidikan Jasmani. Diunduh Dari Http://Ejournal.Unsub.Ac.Id/Index.P hp/Fkip/Article/View/141. Vol 4(2), 2461-3961.

Asrul. (2018). Upaya Meningkatkan Motivasi Belajar Siswa Melalui Kkegiatan Permainan Dalam Pembelajran Pendidikan Jasmani Dan Olahraga Dan Kesehatan Di Kelas Ix Smpn 3 Pasir Penyu. Diunduh Dari Https://Jptam.Org/Index.Php/Jptam/ Article/View/113. Vol 2(5), 12211237.

Ateng Abdulkadir (1993). Azas Dan Landasan Pendidikan Jasmani Dan Olahraga. Jakarta, Departemen Pendidikan Dan Kebudayaan

Byl, J, \& Kloet, V, B. (2014). Physical Education For Homeshool, Classrom, And Recreation Settings. Human Kinetics.

Corbin, C.B., Mc Connell, K. E., Masurier, L.G. C., Corbin, D. E., \& Farrar, T. D. (2014). Health Opportunitis Through Physical Education. Human Kinetics.

Dalton, William., Rachman, H, A. (2014). Modifikasi Model Pembelajaran Sport Education Berbasis Kejuaraan Untuk Guru Penjas SMP. Diunduh Dari
Https://Journal.Uny.Ac.Id/Index.Php /Jolahraga/Article/View/2607/2162. Vol 2 (1), 106-118.

Demir, K. 2011. Teachers Intrinsic And Extrinsic Motivation As Predictors Of Student Engagement. New World Science Academy. 6(2). 1397-1409.

Depdiknas. (2003) Tes Kesegaran Jasmani Indonesia. Pusat Pengembangan Kualitas Jasmani.

Fahey, T. D., Insel, P., Roth, W.T., \& Insel, C. (2015). Fit \& Well Core Concepts And Labs In Physical Fitness And Wellness. Mcgraw-Hill Eucation: New York.

Fikri, Azizil. (2017). Meningkatkan Kebugaran Jasmani Melalui Metode Latihan Sirkuit Dalam Pembelajaran Pendidikan Jasmani Olahraga Dan Kesehatan Di SMA Negeri 1 Lubuklinggau. Diunduh Dari Http://Ojs.Unpkediri.Ac.Id/Index.Ph p/Pjk/Article/View/736. Vol 3 (1), 89-102

Gu, X., \& Chang, M. (2016). Physical Activity, Physical Fitness, And Health Related Quality Of Life In School-Aged Children. Diunduh Dari Jurnal Of Teaching In Physical Education. Http://Www.Who.Int/Dietphysicalac tivity/Factsheet_Young_People/En/. Vol 35. 117-126

Hamalik, O. (2010). Psikologi Belajar \& Mengajar.Bandung. Sinar Baru Algesindo.

Hartati, S.C.Y., Priambodo, A \& Kristiyandaru, A. (2012). Permainan Kecil. Surabaya. Wineka Media.

Hartono, Dkk. (2013). Pendidikan Jasmani (Sebuah Pengantar). Surabaya: Unesa University Press.

Hyvonen, P. T. (2011). Play In The School Context? The Perspectives Offinnish Teachers. Australian Journal Of Teacher Education. 36(8). 49-67.

Kementerian Pendidikan Dan Kebudayaan Republik Indonesia. (2014). Pendidikan Jasmani, Olahraga, Dan Kesehatan. Jakarta. 
Kristiyandaru, A. (2012). Manajemen Pendidikan Jasmani Dan Olahraga. Surabaya: Unesa University Press.

Lutan, Rusli. (2001) Asas-Asas Pendidikan Jasmani. Jakarta: Departemen Pendidikan Nasional

Maksum, A. (2011). Psikologi Olahraga Teori Dan Aplikasi. Surabaya. Unesa University Press.

Maksum, A. (2012). Metodologi Penelitian Dalam Olahraga. Surabaya: Unesa University Press.

Muhyi, M, (2011). Keefektifan Program Pendekatan Jinestetik Terhadap Kesegaran Jasmani Dan Perkembangan Karakter Siswa. Desertasi Tidak Diterbitkan. Surabaya: Pascasarjana Unesa

Mutaqin, Latif. (2018). Upaya Meningkatkan Kebugaran Jasmani Melalui Circuit Training. Diunduh Dari Https://Jurnal.Unimed.Ac.Id/2012/In dex.Php/Jik/Article/View/6103. Vol 14 (1), 1-10

Mutohir. T.C., \& Maksum. A. (2006). Sport Development Index. Jakarta: $\mathrm{Pt}$ Indeks.

Nurhasan. (2011). Menjaga Kebugaran Jasmani. Abil Pustaka.

Nurlatifah, Widia, Subarjah,Herman \& Supriyadi, Tedi. (2018) Pengaruh Mmetode Bermain Terhadap Motivasi Belajar Siswa Dalam Pendidikan Jasmani. Diunduh Dari Https://Docplayer.Info/123207120-

Pengaruh-Metode-Bermain-

Terhadap-Motivasi-Belajar-SiswaDalam-Pendidikan-Jasmani.Html. Vol. 3(4). 181-190.

Physical Fitness Preparation Guide Tamara Spaulding, Lead Physical Fitness Instructor. (2015). Broward College Instute Of Public Safty Low Enforcemen And Corrections Academy Physical Fitness Preparation Guide.

Quinn, T \& Eckerson T. (2010). Motivating Students To Read With Collaborative Reading Quizzes. National Council Teacher Of English. 100 (1). 89-91. Di Akses Pada Tanggal 23 Februari
2017.

Https://Eric.Ed.Gov/?Id=Ej896466

Rahayu, E.T. (2013). Strategi Pembelajaran Pendidikan Jasmani. Bandung: Alfabeta.

Riduwan. (2013). Dasar-Dasar Statistika. Bandung: Alfabeta.

Sahroni, Bahar. (2016). Pengaruh Penerapan Permainan Kecil Terdahap Motivasi Siswa Dalam Mengikuti Pembelajaran Pendidikan Jasmani, Olahraga Dan Kesehatan (Pada Siswa Kelas XI SMAN 1 Kecamatan Pulung, Kabupaten Ponorogo). Diunduh Dari Https://Jurnalmahasiswa.Unesa.Ac.I d/Index.Php/Jurnal-PendidikanJasmani/Article/View/19715. Vol 4(3), 674-678.

Saputra, Iwan. (2015). Pengaruh Metode Circuit Training Terhadap Peningkatan Kebugaran Jasmani Siswa Putra Kelas Va Dan Vb Sekolah Dasar Negeri 112321 Kampung Pajak Kabupaten Labuhan Batu Utara. Diunduh Dari Https://Journal.Uny.Ac.Id/Index.Php /Jpji/Article/View/21339. Vol 14 (1), 58-67.

Setyorini. (2016). Pengaruh Program Live Life Well At School Dan Reward Terhadap Keterampilan Gerak Dasar. Tesis Tidak Diterbitkan. Surabaya: Pascasarjana

Shape Of The Nation. (2016).Shape Of The Nation Status Of Physical Education In Usa. Shape America

Singh, I., Malik, Singh, C., \& Rajesh. (2015). A Comparative Study Of Physical Fitness Variables Among The Haryana's Football Players. International Jurnal Of Applied Research, Vol. 1 (11), 104-106.

Soemitro, (2000). Permainan Kecil. Depdiknas.

Sriundy, M. M. (2014). Evaluasi Pengajaran. Surabaya: Unesa University Press.

Sudjana. (2005). Metoda Statistika. Bandung: Pt. Tarsito Bandung. 
Sugiyono. (2017). Penelitian Kuantitatif,

Kualitatif Dan Pengembangan R\&D. .Bandung: Alfabeta.

Supendi, P \& Nurhidayat. (2016). 50 Permainan Indoor Dan Outdoor Mengasyikkan. Jakarta. Penebar Plus.

Supranto, J \& Limakrisna, N. (2012). Petunjuk Praktis Penelitian Ilmiah Untuk Menyusun Skripsi, Tesis, Dan Disertasi. Jakarta: Mitra Wacana Media

Tegeh, Made. Jampel, Nyoman. Pudjawan, Ketut. (2016). Model Penelitian Pengembangan. Jakarta: Graha Ilmu.

Ullah, M. I., Sagheer, A., Sattar, T., \& Khan, S. (2013). Factors Influencing Students Motivation To Learn In Bahauddin Zakariya University, Multan (Pakistan).International Journal Of Human Resource Studies. 3(2). 90-108.

Unesa. (2015). Pedoman Penulisan Tesis Dan Desertasi Program Pascasarjana. Surabaya. Pps Universitas Negeri Surabaya.

Uno, H. B. (2013). Teori Motivasi \& Pengukurannya. Gorontalo: Bumi Aksara.

Wibowo, Hari. (2018). Judul Motivasi Belajar Siswa Dalam Pembelajaran Pendidikan Jasmani Materi Ajar Passing Bawah Dalam Permainan Bola Voli Pad Siswa Kelas VII SMP Negeri 2 Majalaya. Diunduh Dari Https://Journal.Unsika.Ac.Id/Index.P $\mathrm{hp/Speed/Article/View/1497.} \mathrm{Vol.}$ 1(1). 45-48.

William, K. C \& William C. C. (2011). Five Key Ingredients For Improving Student Motivasion.Research In Higher Educatin Journal. 12, 1-23 